Sharif University of Technology
Scientia Iranica
SCIENTIA
I RAN ICA
http://scientiairanica.sharif.edu

\title{
Analysis of influencing factors on rutting resistance of stone matrix asphalt mixtures
}

\author{
R. Guo* \\ School of Civil Engineering and Architecture, Shaanxi University of Technology, Hanzhong, Shannxi, China.
}

Received 17 May 2017; received in revised form 26 September 2017; accepted 2 July 2018

\section{KEYWORDS}

Road engineering; Rutting resistance; Influencing factors; Stone matrix asphalt; Prediction model.

\begin{abstract}
Rutting deformation not only shortens the service life of asphalt pavement, but also brings great risks to the drivers. The rutting resistance of Stone Matrix Asphalt (SMA) is affected by many factors. This study aimed to thoroughly discuss the main factors of rutting resistance and establish a dynamic stability prediction model based on experimental data from Marshall testing and wheel tracking test of SMA mixtures. The results showed that the optimal dosage of bitumen in rutting test was $0.1 \sim 0.3 \%$ more than that in Marshall testing for SMA mixtures. With $0.5^{\circ} \mathrm{C}$ increase in temperature, dynamic stability of SMA mixtures decreased by an average of $18.6 \%$. Also, greater amounts of aggregate and mineral powder did not lead to better rutting resistance of SMA mixtures. With too much or too little compaction work, the rutting resistance of SMA mixtures was reduced. There was a positive correlation between dynamic stability of SMA mixtures and fractal dimension, relative coefficient, and asphalt content, while the correlation between dynamic stability of SMA mixtures and rolling times as well as testing temperature was negative.
\end{abstract}

(C) 2020 Sharif University of Technology. All rights reserved.

\section{Introduction}

In the past two decades, economic competitiveness and productivity in nearly all developing and developed countries have become a major challenge. Economic growth has given rise to the production level of goods and creation of transportation facilities used for the delivery of products and floating population [1]. Therefore, the transportation facilities have been carrying more and more goods and the volume of traffic on the roads has increased, leading to the fast deterioration and decomposition of asphalt pavements [2]. Rutting deformation is one of the most prominent diseases in the early damage of asphalt pavements, which not only shortens their service life [3-5], but also brings great se-

\footnotetext{
*. Tel.: +869162641947

E-mail address: grlch2356@163.com
}

curity risks to drivers. Therefore, a new design method is needed to improve the performance and effective service life of asphalt concrete road. Using SMA is an approach to the improvement of rutting resistance of asphalt pavement [6] and the application of SMA to the construction of the roads has been proven to increase durability of asphalt road surfaces [7].

Stone Matrix Asphalt (SMA) is a hot asphalt mixture that was first created in Germany during the mid-1960s and has been used in Europe for more than 20 years to provide better rutting resistance, to resist tire wear, and to prevent sliding [8]. Also, more than 28 states in the United States of America have turned to SMA pavements $[9,10]$. After its successful application in Europe and the USA, the first SMA pavement was constructed in China in 1993. Since then, the number of SMA pavements has significantly increased and they have been promoted nationwide by the ministry of transport of China [11].

SMA is a gap-graded aggregate hot asphalt mix- 
ture that has higher proportion of coarse aggregate, lower proportion of middle-size aggregate, and higher proportion of mineral filler than a dense-graded mixture containing $70 \%-80 \%$ coarse aggregate, $6 \%-7 \%$ binder, and $8 \%-12 \%$ filler [12]. It provides an efficient network with a stable stone-on-stone skeleton. Other characteristics of SMA are well wedging force among coarse aggregates and low porosity [13-17]. The significant differences of SMA from continuous dense gradation asphalt mixtures are its stabilized stone with dense skeleton and high content of asphalt with $6-7.5 \%$ total weight of the mixture $[18,19]$. Studies have shown that SMA mixture has high resistance to deformation with high coarse aggregate content interlocked to form a stone skeleton that is more durable and rutting resistant than the conventional asphalt mixtures [2023]. In comparison, it provides $33-103 \%$ longer service life and increased durability up to $20 \%-30 \%$ [24]. Since SMA pavements have a high capability of rutting resistance, they have drawn more and more attention of the engineers and technicians in the field of roads.

The rutting resistance of asphalt mixtures is affected by many factors, including internal and external ones. The major influencing factors are bitumen dosage, compaction energy, test temperature, and gradation composition [25]. These factors also have an impact on the anti-rutting deformation of SMA mixtures. Some researchers [26-28] studied and validated the effects of asphalt content and aggregate structure on the rutting resistance of SMA from different perspectives. Others $[29,30]$ concluded that the type and amount of mineral filler played a major role in the behavior of SMA and its mastics. Xie [31] analyzed the optimum compaction effect in SMA mixtures that might offer higher durability and better rutting resistance. Through laboratory tests, Behbahani et al. [32] studied the change of fiber type and content, which could cause considerable variation in rutting performance of SMA. As observed in the review of the literature, researchers have analyzed the anti-rutting performance of SMA mixtures in terms of only one of the major factors, e.g. bitumen content, aggregate structure, compaction energy, etc., and there is rare research on the rutting resistance of SMA mixtures with regard to multiple influencing factors.

The objective of this study is to investigate the rutting resistance of SMA mixtures under the influence of asphalt dosage, compaction energy, gradation composition, and test temperature as well as to determine the optimum level for every influencing factor. Then, based on the achieved results, the prediction model for dynamic stability of SMA pavement is established by taking into account the relative coefficient corresponding to the continuity of aggregate gradation, fractal dimension corresponding to the distribution of aggregate size, asphalt content, rolling times corresponding to the compaction effort, and temperature corresponding to the surface temperature of the road in summer as the parameters of the model. These parameters would be significantly helpful in improving the anti-rutting performance of SMA concrete pavements.

\section{Materials}

\subsection{Asphalt used}

In SMA mixtures, the asphalt binder should have good adhesion with the aggregate. The AH-90 heavy traffic petroleum asphalt produced by Lanzhou Petrochemical Company of Petro China was used in this study. The main properties of the asphalt used are given in Table 1.

\subsection{Aggregate used}

The aggregate and mineral filler used in the tests were supplied by a quarry about $30 \mathrm{~km}$ away from the laboratory and the aggregate made from sandstone in different size standards was obtained after two steps of crushing, grinding, classification, and gravity separation. The physical properties of the aggregate and mineral powder are presented in Tables 2 and 3, respectively.

In this study, three aggregate gradations (S-1, S-2, and S-3 corresponding to the upper-, mid-, and

Table 1. Physical properties of the asphalt used.

\begin{tabular}{lcc}
\hline \multicolumn{1}{c}{ Material properties } & Actual value \\
\hline Penetration $\left(25^{\circ} \mathrm{C}, 100 \mathrm{~g}, 5 \mathrm{~s}\right)$ & $0.1 \mathrm{~mm}$ & 95.2 \\
Wax content $(\%)$ & & 2.55 \\
Specific gravity $\left(\mathrm{g} . \mathrm{cm}^{-3}\right)$ & 0.996 \\
Solubility $(\%)$ & 99.59 \\
Flash point $\left({ }^{\circ} \mathrm{C}\right)$ & 332.0 \\
Softening point $\left({ }^{\circ} \mathrm{C}\right)$ & 47.6 \\
Ductility $(\mathrm{cm})$ & $15^{\circ} \mathrm{C}$ & $>150$ \\
& $10^{\circ}$ & 72 \\
Dynamic viscosity $\left(60^{\circ} \mathrm{C}\right) /(\mathrm{Pa} . \mathrm{S})$ & & 165.2 \\
\hline
\end{tabular}

Table 2. Physical properties of the aggregate used.

\begin{tabular}{|c|c|}
\hline Characteristic & Actual value \\
\hline Water absorption (\%) & 1.2 \\
\hline Aggregate and asphalt adhesion (grade) & 5.5 \\
\hline L.A. abrasion (\%) & 20.4 \\
\hline Flakiness (\%) & 9.5 \\
\hline Rock powder (g.cm ${ }^{-3}$ ) & 2.8 \\
\hline \multicolumn{2}{|l|}{ Specific gravity-apparent (g.cm $\left.{ }^{-3}\right)$ : } \\
\hline $10 \sim 20(\mathrm{~cm})$ & 3.52 \\
\hline $5 \sim 10(\mathrm{~cm})$ & 1.50 \\
\hline Stone chippings & 1.43 \\
\hline
\end{tabular}


Table 3. Physical properties of the mineral filler used.

\begin{tabular}{lc}
\hline \multicolumn{1}{c}{ Characteristic } & Actual value \\
\hline Apparent relative density $\left(\mathrm{g} . \mathrm{cm}^{-3}\right)$ & 2.81 \\
Water content $(\%)$ & 0.89 \\
Appearance & No agglomeration \\
Hydrophilic coefficient & $\ll 1$ \\
\hline
\end{tabular}

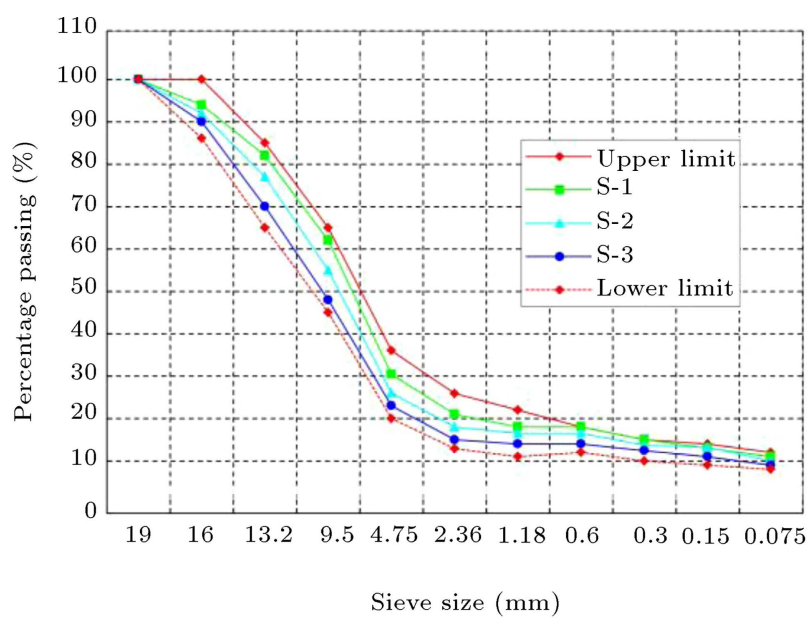

Figure 1. The curves of the three gradations used.

the lower-limit gradations of SMA, respectively) with nominal maximum aggregate size of $19 \mathrm{~mm}$ were chosen to compare test results and analyze the influence of aggregate composition on the anti-rutting performance of SMA mixtures. The curves for the three gradations used are given in Figure 1.

\subsection{Asphalt modifier}

In this experiment, a thermoplastic styrene butadiene rubber with linear appearance and white stripe (as presented in Figure 2), produced by a petrochemical company named Yanshan in China, was used as asphalt modifier. The main properties of the asphalt modifier are listed in Table 4.

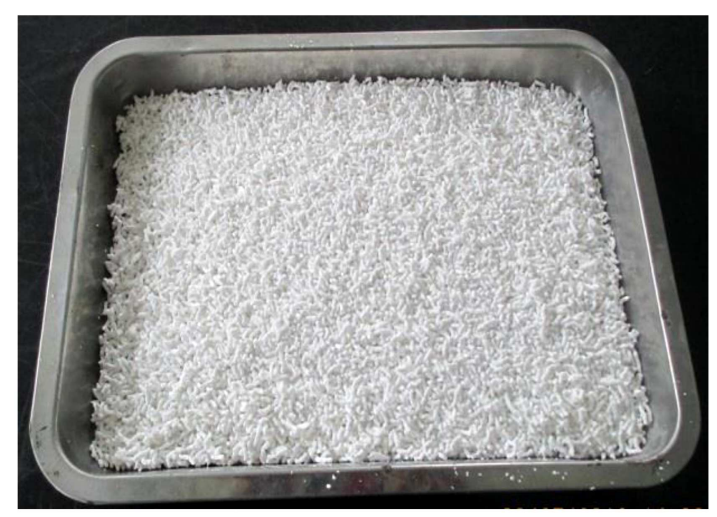

Figure 2. SBS asphalt modifier.
Table 4. Physical properties of the asphalt modifier used .

\begin{tabular}{cccc}
\hline $\begin{array}{c}\text { Surface } \\
\text { appearance }\end{array}$ & $\begin{array}{c}\text { Density } \\
(\text { g.cm }\end{array}$ & $\begin{array}{c}\text { Particle } \\
\text { diameter } \\
(\mathbf{m m})\end{array}$ & $\begin{array}{c}\text { Melting } \\
\text { point } \\
\left({ }^{\circ} \mathbf{C}\right)\end{array}$ \\
\hline White linear & 0.78 & $3 \sim 6$ & 142 \\
\hline
\end{tabular}

\section{Experimental method}

In this research work, testing was carried out in two steps. In the first step, the volume of SMA mixtures was measured through Marshall testing. To do so, four asphalt contents and six volume indicators were classified as S-1, S-2, and S-3 mixtures by the abovementioned standards [33]. Then, 4 parallel samples (as shown in Figure 3) were fabricated in laboratory by a Marshall compaction device (as shown in Figure 4). Samples were made for each considered volume with different bitumen dosages and the volume index of Marshall test for asphalt mixture was taken as the result. The Optimum Asphalt Content (OAC) in

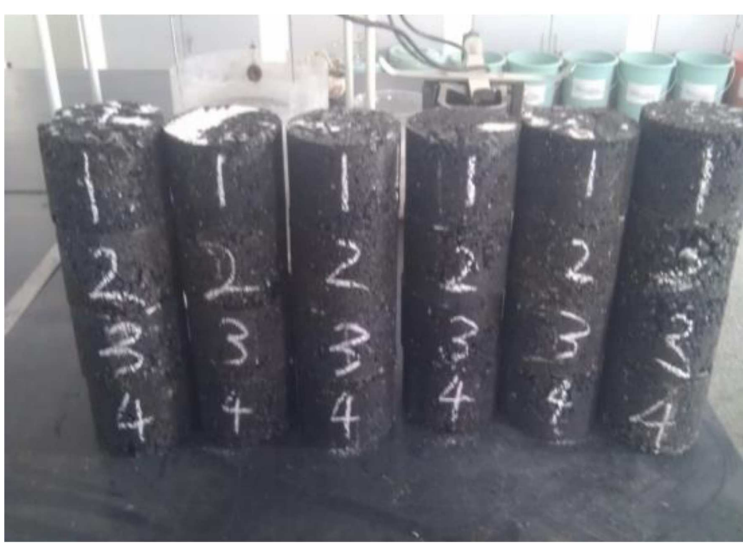

Figure 3. Marshall testing samples.

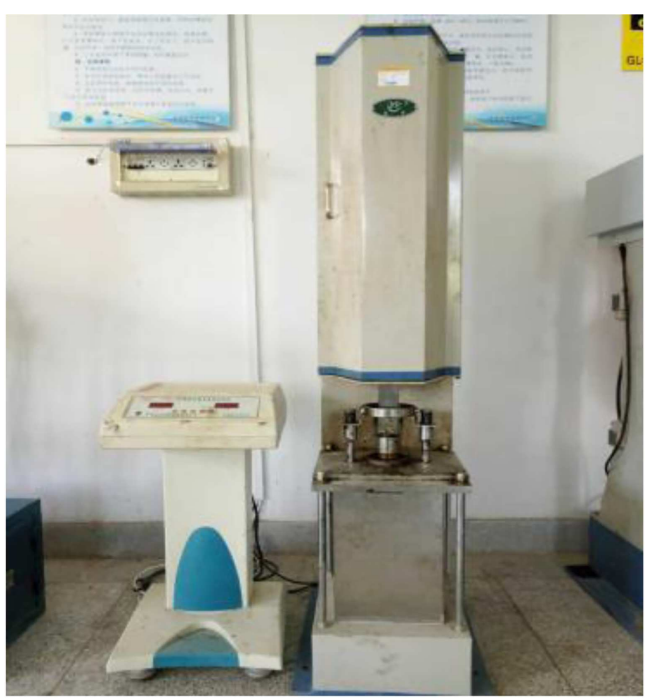

Figure 4. Marshall testing device. 
Marshall testing was obtained for every mixture by the curve between volume index and asphalt content, which was drawn on the same chart to find the asphalt dosage of every index [33]. In the second step, the influence of the factors including asphalt dosage, gradation composition, testing temperature, and compaction energy on the rutting resistance of SMA mixtures was analyzed by wheel tracking test. The four-level asphalt for each mixture was obtained by floating $0.1 \% \sim 0.3 \%$ basing on OAC. The track plate specimens (length $300 \mathrm{~mm}$, width $300 \mathrm{~mm}$, thickness $50 \mathrm{~mm}$ ) were prepared by rolling machine with $98 \%$ compaction effect (as presented in Figure 5). The three samples for each asphalt content were the same and a total of 36 cubes were prepared. The rut samples were cooled $24 \mathrm{~h}$ at room temperature and then placed in the rutting instrument $\left(60 \pm 0.5^{\circ} \mathrm{C}\right.$ internally). Afterwards, they were continuously heated $5 \mathrm{~h}$ for the simulating high-temperature effect. After preparing the conditions, the rut test instrument was run at tire pressure of $0.7 \mathrm{MPa}$ (Figure 6). After an hour, dynamic stability of the mixtures was evaluated by data acquisition.

In this study, the main test instrument used was

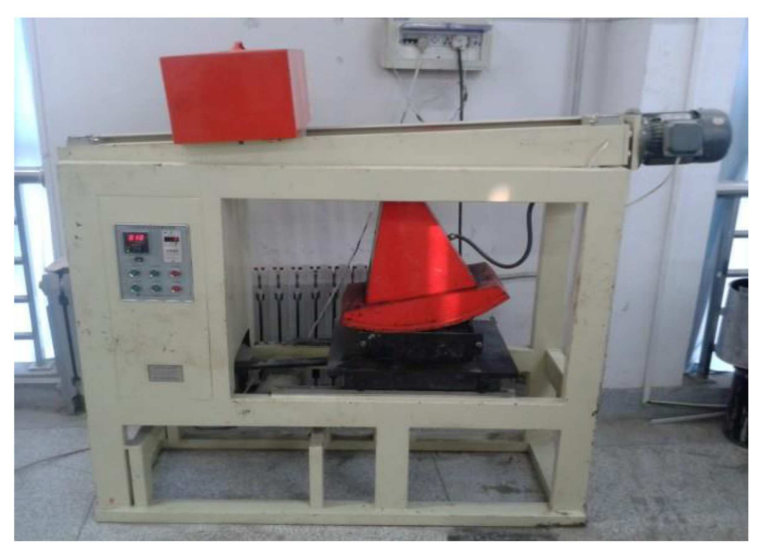

Figure 5. Rutting samples manufactured.

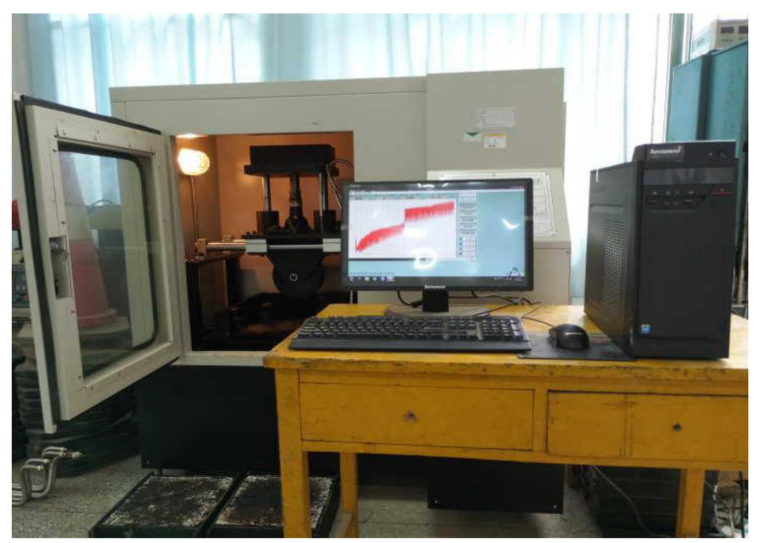

Figure 6. Rutting test of Stone Matrix Asphalt (SMA) mixtures. a Marshall compact device for wheel rolling and wheel tracking (as shown in Figures 4, 5, and 6). Dynamic stability test was conducted by the testing system of the wheel tracking instrument, which was composed of hydraulic power supply, environmental chamber, control system, and data acquisition system. The instrument has been proved in the literature; also, it obtains accurate and reliable experimental data [3436]. At present, it is widely used by road research institutions in China.

\section{Experimental results and discussion}

\subsection{Marshall test results}

In this paper, the asphalt dosage of $5.7 \%$ was primarily determined for S-1, S-2, and S-3 gradations in Marshall testing based on the standards of P.R.C. Ministry of Communications [33] as well as experimental results and tests in the literature [19]. Four different bitumen contents with the change rate of $0.3 \%$ were prepared for each gradation mixture such that S-1 and S-2 had the contents of $5.4 \%, 5.7 \%, 6 \%$, and $6.3 \%$ and $\mathrm{S}-3$ had $5.2 \%, 5.5 \%, 5.8 \%$, and $6.1 \%$. The volume indices (BG: bulk specific gravity of bituminous mixtures; VV: percentage of air voids in asphalt mixtures; VFA: percentage of voids in the mineral aggregate that are filled with asphalt in bituminous mixtures; VMA: percentage of voids in the mineral aggregate in asphalt mixtures; FL: flow value: MS: Marshall Stability) of SMA mixtures with varying contents are shown in the figures.

As seen in Figure 7, with increase in asphalt, the bulk specific gravity (BG) and Marshall Stability (MS) of SMA mixtures with different gradations first increase and then, decrease; also, the percentage of air voids $(\mathrm{VV})$ is gradually reduced as the surface of the aggregates is fully covered and the space between them is filled in asphalt mixtures. Accordingly, the percentage of voids in the mineral aggregate filled with asphalt (VFA) increases. The percentage of voids in the mineral aggregate (VMA) first decreases and then, increases with increase in asphalt dosage. The reason is that when the asphalt dosage is less than OAC, VMA gradually decreases by bitumen filling with the increased asphalt content. However, as asphalt content becomes more than OAC, the gap between the aggregates is opened up by the excess asphalt, which leads to higher VMA. With increase in asphalt content, the flow of SMA mixtures takes an increasing trend, because as asphalt content is above the optimum amount, the excess bitumen plays the role of a lubricant between aggregates leading to their slipping.

According to Figure 7 and the standards of P.R.C. Ministry of Communications [37], the asphalt contents for the maximum Marshall Stability (MS) and bulk specific gravity (BG) are $a_{1}=a_{2}=6.3 \%, 6.2 \%$, $5.8 \%$; for the medium value of the percentage of air 


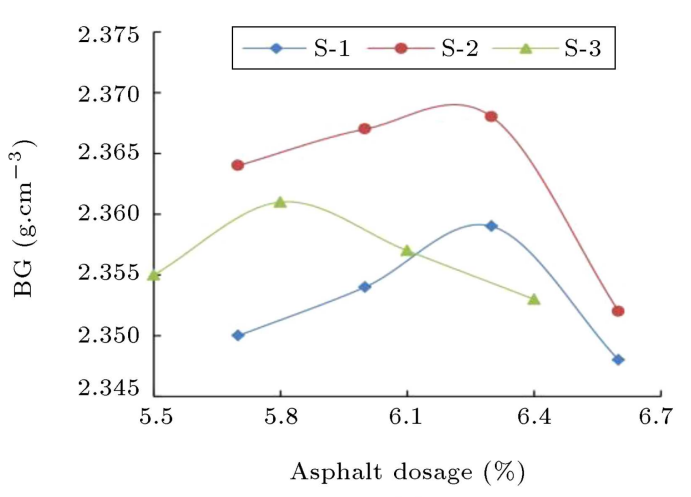

(a)

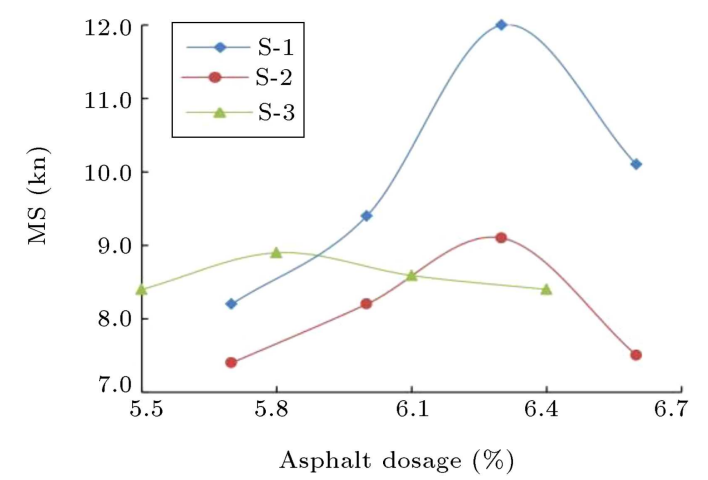

(c)

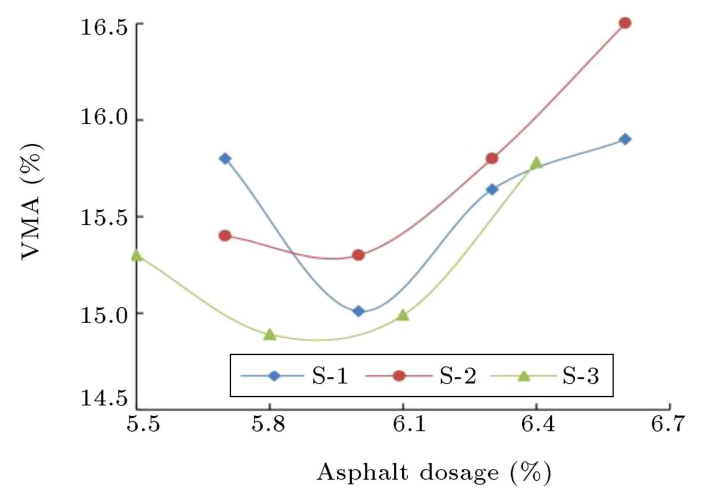

(e)

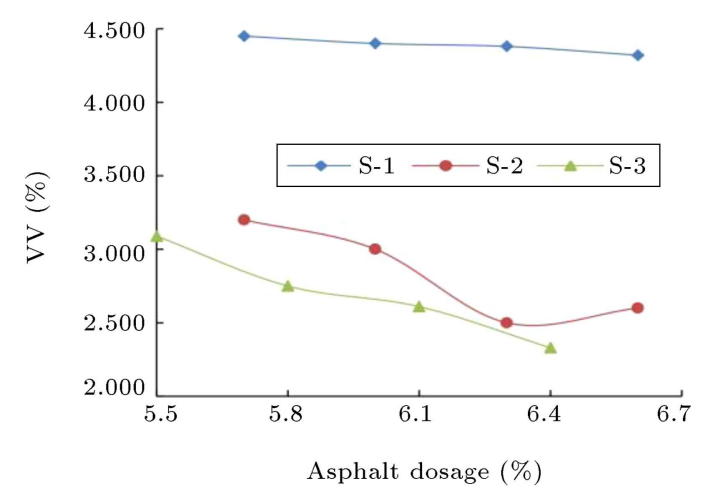

(b)

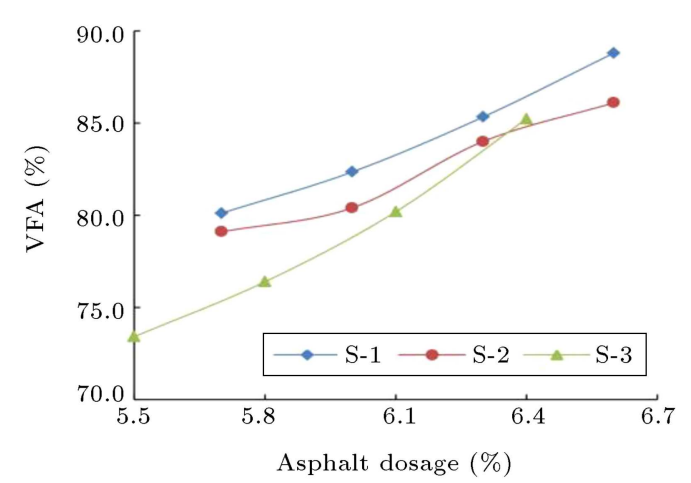

(d)

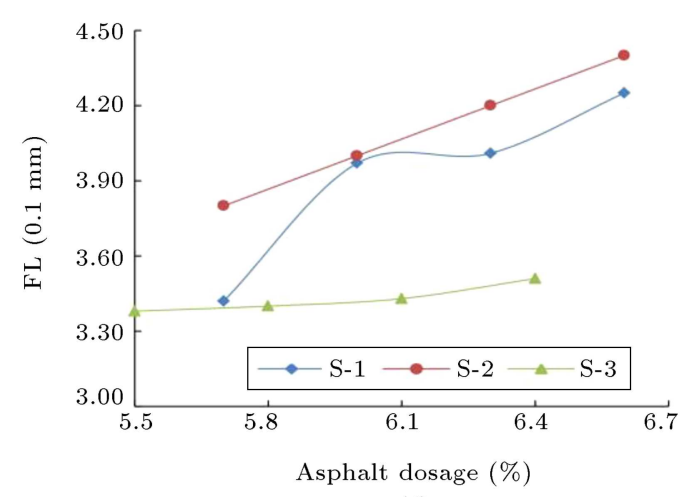

(f)

Figure 7. The relationship between volume index and asphalt content in Stone Matrix Asphalt (SMA) mixtures.

voids $(\mathrm{VV})$ are $a_{3}=6.3 \%, 6.2 \%, 6.0 \%$; and for the medium value of the percentage of voids in the mineral aggregate filled with asphalt (VFA) are $a_{4}=6.2 \%$, $6.2 \%, 6.0 \%$ for S-1, S-2, and S-3 asphalt mixtures, respectively. The initial value of $\mathrm{OAC}$ for $\mathrm{S}-1, \mathrm{~S}-2$, and S-3 mixtures is $O A C_{1}=\left(a_{1}+a_{2}+a_{3}+a_{4}\right) / 4=$ $6.25 \%, 6.20 \%, 6.12 \%$. The $\min$ and $\max$ values of asphalt content that can meet the requirements of the standards [37] are $O A C_{\min }=6.2 \%, 6.1 \%, 5.8 \%$ and $O A C_{\max }=6.3 \%, 6.2 \%, 6.1 \%$. Thus, $O A C_{2}=$ $\left(O A C_{\min }+O A C_{\max }\right) / 2=6.25 \%, 6.15 \%, 5.95 \%$. Accordingly, the optimum dosage for S-1, S-2, and S-3 mixtures is $O A C=\left(O A C_{1}+O A C_{1}\right) / 2=6.25 \%, 6.2 \%$, $6.0 \%$. The Marshall testing results for SMA mixtures under OAC are shown in Table 5.

\subsection{Effect of asphalt dosage}

Based on the OAC values determined by Marshall test, four asphalt dosages were selected for the SMA-1, SMA-2, and SMA-3 asphalt mixtures (corresponding to S-1, S-2, and S-3, respectively) to study the effect of asphalt cement on the anti-rutting performance of SMA and to identify the proper asphalt dosage in SMA mixtures in the wheel test. The results are given in Figure 8.

They obviously indicate that there is high correlation, up to 0.9 , between asphalt dosage and dynamic stability in different aggregate gradations. With increase in asphalt content, the dynamic stability of SMA-1, SMA-2, and SMA-3 first increases and then, decreases. The curves of bitumen content and dynamic 
Table 5. Marshall results for the three Stone Matrix Asphalt (SMA) mixtures.

\begin{tabular}{|c|c|c|c|c|c|c|c|c|c|}
\hline & & \multicolumn{8}{|c|}{ Index } \\
\hline & & $\begin{array}{c}\text { OAC } \\
(\%)\end{array}$ & $\begin{array}{l}\text { VV } \\
(\%) \\
\end{array}$ & $\begin{array}{c}\text { VMA } \\
(\%) \\
\end{array}$ & $\begin{array}{l}\text { VFA } \\
(\%)\end{array}$ & $\begin{array}{c}\text { VCA }_{\text {mix }} \\
(\%)\end{array}$ & $\begin{array}{c}\text { VCA }_{\text {DRC }} \\
(\%)\end{array}$ & $\begin{array}{c}\mathrm{MS} \\
(\mathrm{kN})\end{array}$ & $\begin{array}{c}\text { FL } \\
(\mathrm{mm})\end{array}$ \\
\hline \multirow{3}{*}{ 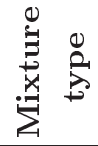 } & S-1 & 6.25 & 3.10 & 17.90 & 82.90 & 37.10 & 40.32 & 7.20 & 4.10 \\
\hline & $\mathrm{S}-2$ & 6.2 & 3.10 & 17.50 & 82.10 & 33.43 & 40.74 & 7.01 & 3.97 \\
\hline & $\mathrm{S}-3$ & 6.0 & 3.90 & 17.91 & 78.20 & 30.35 & 41.46 & 6.51 & 3.53 \\
\hline
\end{tabular}

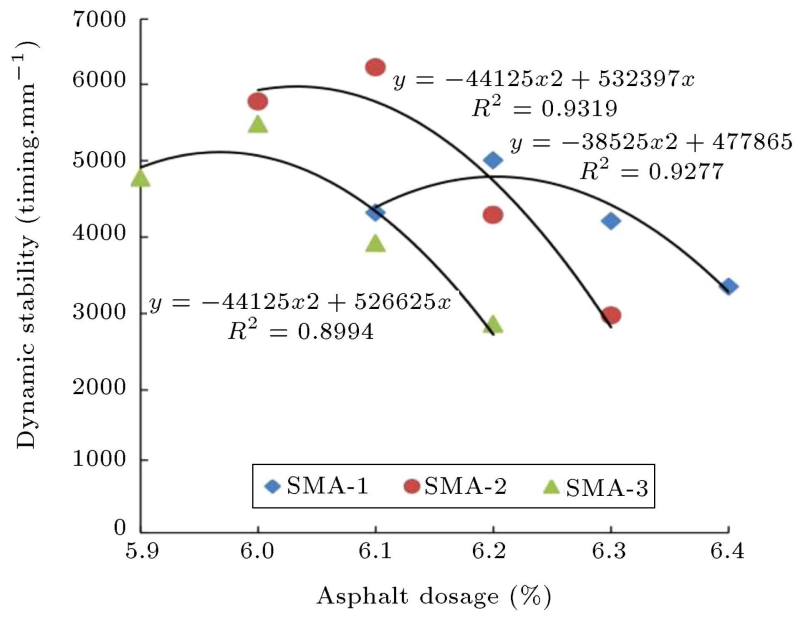

Figure 8. The relationship between asphalt dosage and dynamic stability in Stone Matrix Asphalt (SMA) mixtures.

stability have an almost parabolic relationship with the OAC (confined $\mathrm{OAC}^{\prime}$ ) in the rutting test of SMA mixtures. The $\mathrm{OAC}^{\prime}$ values for SMA-1, SMA-2, and SMA-3 mixtures are $6.1 \%, 6.2 \%$, and $6.0 \%$. They are obviously different from those in Marshall testing (OAC). The relation between $\mathrm{OAC}$ and $\mathrm{OAC}^{\prime}$ agrees with the formula:

$O A C=O A C+0.1 \% \sim 0.3 \%$.
The influence of asphalt content on the dynamic stability of SMA mixtures could be interpreted as follows. As asphalt content is less than $\mathrm{OAC}^{\prime}$, it is prone to rutting deformation in SMA mixtures, because a stable skeleton structure is difficult to form in SMA mixtures when the surface of mineral powder and fine aggregate cannot be fully wrapped by the asphalt. As a result, the cohesion of coarse aggregates decreases. When the asphalt content is more than $\mathrm{OAC}^{\prime}$, the anti-rutting capability of SMA mixtures decreases with increase in asphalt content, because the excess asphalt plays the role of a lubricant between coarse aggregates and improves lubrication between aggregate surfaces. Therefore, it is not feasible to improve rutting resistance of SMA pavement only by increasing the amount of asphalt.

\subsection{Effect of compaction energy}

Three rolling times (12, 18, and 24 times, respectively) were selected for manufacturing rut samples based on the standards [33] to simulate the compaction work in a practical project. The amounts of bitumen used for making rutting specimens were determined by the $\mathrm{OAC}^{\prime}$ of three gradations of SMA mixtures. The test results are reported in Table 6 .

As shown in the table, in all the three gradations of SMA mixtures under the same experimental conditions, in comparison with compaction for 12 times, the

Table 6. Test results for dynamic stability of Stone Matrix Asphalt (SMA) mixtures under various compaction work.

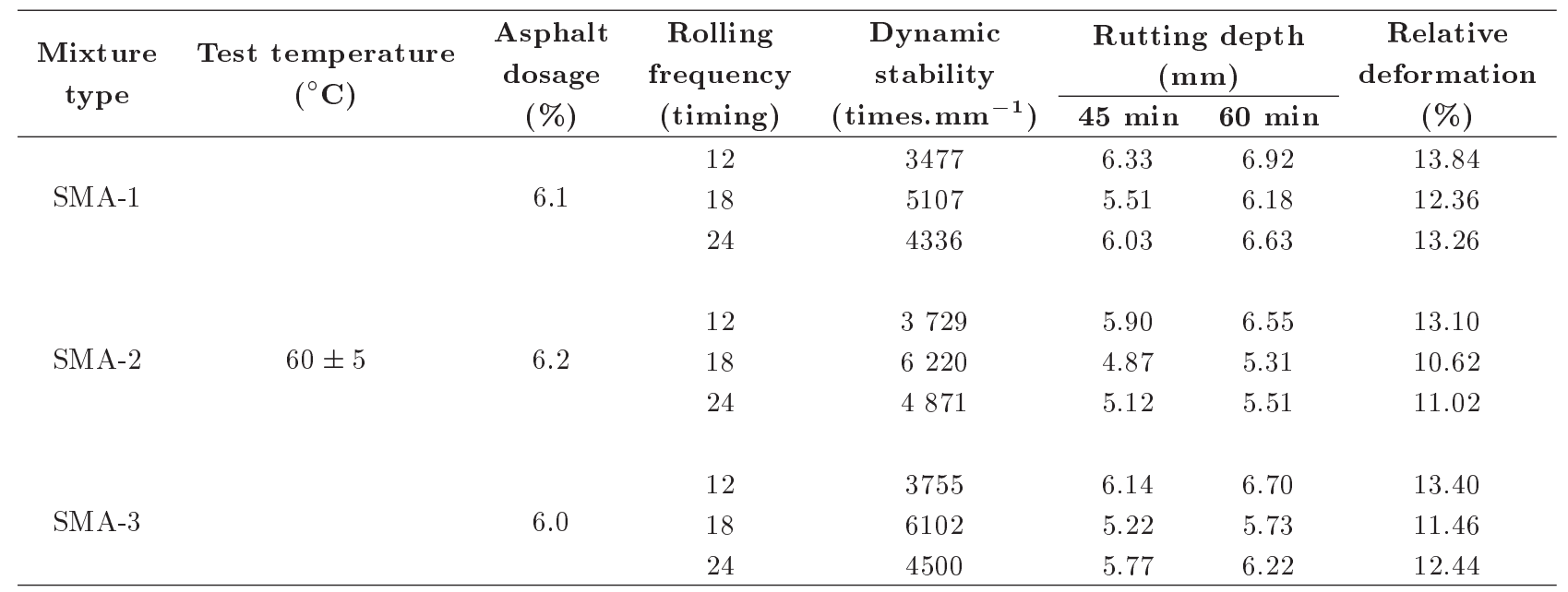


dynamic stability of compaction for 18 times increases by $66.8 \%$. However, dynamic stability of compaction for 24 times is $23.16 \%$ lower than that for 18 times. The reason is that when the number of compactions is less than 18 times, an embedded skeleton structure between coarse aggregates is difficult to form in SMA mixtures without compaction work. However, in case of compaction for 24 times, the skeleton framework formations of SMA mixtures are rapidly deteriorated by over-extrusion of coarse aggregates subjected to too high compressive stress. It can be concluded that too much or too little compaction work will reduce the antirutting performance of SMA pavement. With increase in rolling times, the dynamic stability of the three SMA gradations follows SMA-2 > SMA-3 > SMA-1, relative deformation is SMA-2 $<$ SMA-3 $<$ SMA-1, and deformation rate is SMA-2 $<$ SMA-3 $<$ SMA-1. Accordingly, the change of relative deformation is exactly opposite to that of dynamic stability. The above result indicates that the optimum compaction work is 18 times for SMA-16 mixture and the parameters of dynamic stability and relative deformation can be used to evaluate the effect of compaction energy on the rutting resistance of SMA pavement.

\subsection{Effect of temperature}

Six temperatures $\left(60^{\circ} \mathrm{C}, 65^{\circ} \mathrm{C}, 70^{\circ} \mathrm{C}, 75^{\circ} \mathrm{C}, 80^{\circ} \mathrm{C}\right.$, and $85^{\circ} \mathrm{C}$, respectively), $\mathrm{OAC}^{\prime}$, and 18 rolling times were selected for manufacturing rut samples according to the standards [33]. The test results are shown in Figure 9.

It can be seen from the figure that the rutting resistance of SMA mixtures is significantly affected by temperature. There is a linear positive correlation between these two parameters up to 0.99 for the three gradations of SMA mixtures. When temperature increases by $5^{\circ} \mathrm{C}$, dynamic stability of the three mixtures decreases by $20 \%, 17.3 \%$, and $18.4 \%$ in SMA-1, SMA2 , and SMA-3, respectively (with the average reduction of $18.6 \%$ ). Under the same test conditions, by raising temperature to $72^{\circ} \mathrm{C}, 80^{\circ} \mathrm{C}$, and $75^{\circ} \mathrm{C}$ in SMA-1, SMA2, and SMA-3, respectively, dynamic stability of the samples does not meet the standard requirements [37] ( $\gg 3000$ timing. $\mathrm{mm}^{-1}$ ). Under the same temperature, the samples in the order of dynamic stability are SMA-2 > SMA-3 > SMA-1, which indicates that the rutting resistance of SMA-2 is the best at high

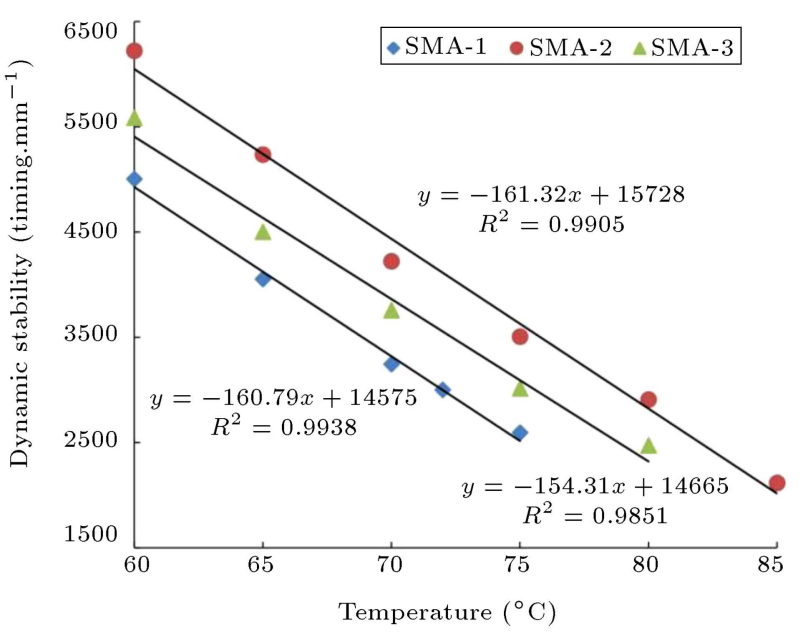

Figure 9. The relationship between test temperature and dynamic stability in Stone Matrix Asphalt (SMA) mixtures.

temperature. The reason is that the content of mineral powder in SMA-1 is more than that in SMA-2, but too much mineral powder results in lower viscosity of asphalt mastic due to increase in filler-asphalt ratio. Also, dynamic stability of SMA-3 is lower than that of SMA-2, because the void among the coarse aggregates is not compacted by the mastic asphalt with insufficient mineral powder, which causes poor stability of the skeleton structure formed by coarse aggregates.

\subsection{Effect of gradation composition}

The gradation of SMA mixtures has a great effect on the performance of pavement road. Three gradations (given in Figure 1), $\mathrm{OAC}^{\prime}$, and rolling for 18 times were considered in preparing the rutting samples. Also, testing temperature was $60 \pm 5^{\circ} \mathrm{C}$. After an hour, both dynamic stability and relative deformation were recorded to measure the indices of the rutting test. The test results are shown in Table 7 .

As observed from the table, the order for the dynamic stability of the three gradations of SMA mixtures is SMA-2 > SMA-3 > SMA-1, for the coarse aggregate content (size $\geq 4.75 \mathrm{~mm}$ ) is $\mathrm{SMA}-3>$ SMA-2 > SMA-1, and for mineral powder is SMA-1 > SMA-2 > SMA-3. This proves that higher amounts of aggregate and powder do not mean better anti-rutting performance of the SMA mixture. It is beneficial to

Table 7. Rutting test results for the three gradations of Stone Matrix Asphalt (SMA) mixtures.

\begin{tabular}{|c|c|c|c|c|}
\hline & \multicolumn{3}{|c|}{ Mix type } \\
\hline & & SMA-1 & SMA-2 & SMA-3 \\
\hline \multirow{4}{*}{ 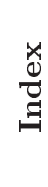 } & Mineral powder (\%) & 11 & 10.1 & 9.5 \\
\hline & Aggregate size $\geq 4.75 \mathrm{~mm}(\%)$ & 70 & 74 & 80 \\
\hline & Dynamic stability (timing. $\mathrm{mm}^{-1}$ ) & 5002 & 6220 & 5583 \\
\hline & Relative deformation (\%) & 12.91 & 10.62 & 12.07 \\
\hline
\end{tabular}


form the framework skeleton structure with a suitable increase in coarse aggregates and mineral powder as well as reduction in fine aggregates as in the SMA-2 mixture. The reason is that the skeleton structure is not affected by interference and expansion of mastic asphalt and the thick material bond increases by expansion in the area covered by aggregates, which is effective in improving resistance to rutting deformation of SMA mixtures. When the skeleton structure is formed with lower amount of mineral powder and higher amount of coarse aggregate, as in SMA-3 mixture, the void among coarse aggregates cannot be fully filled by the mastic asphalt and the mixture becomes prone to deformation and failure. It is also illustrated in Table 7 that under the same experimental conditions, the order of the relative deformation for SMA mixtures is SMA-1 > SMA-3 > SMA-2, which is exactly opposite to dynamic stability. The results demonstrate that the indices of dynamic stability and relative deformation can be used to evaluate the effect of aggregate gradation on the rutting resistance of SMA mixtures.

\section{Prediction model for dynamic stability of SMA mixtures}

There is a favorable agreement between the above experimental results for the single factor of dynamic stability of SMA mixtures and the reference literature [38,39]. The prediction model for the dynamic stability of SMA mixtures is established by taking into account the relative coefficient, $R$, representing aggregate grading characteristics, fractal dimension, $D$, representing size distribution of aggregates, asphalt content, $C$, rolling times, $N$, representing pavement compaction work, and temperature, $T$, as the parameters (as given in Table 8). The model is created in the following steps:

1. Generation and processing of the data. The coefficient $x_{i}^{(0)}$ (represented in Table 9 ) is taken by initial processing of the raw data on three gradations of SMA mixtures shown in Table $8 . x_{i}^{(1)}$ in Table 10 is achieved by accumulating procession of $x_{i}^{(0)}$.

2. Calculating sequence $\hat{a}$. The sequence $\hat{a}$ is obtained by adopting the calculation procedure. In the first step, a sequence $Z_{1}^{(1)}$ is formed, which can be
Table 9. Initial processing of raw data on Stone Matrix Asphalt (SMA) mixtures.

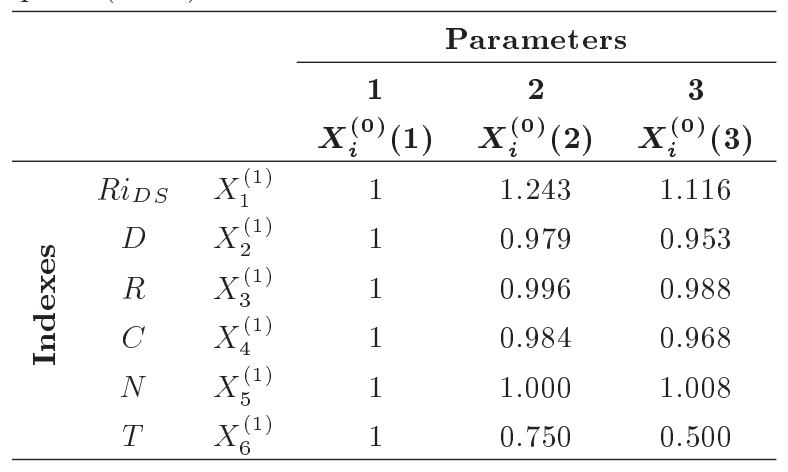

Table 10. Results of accumulation treatment $x_{i}^{(0)}$.

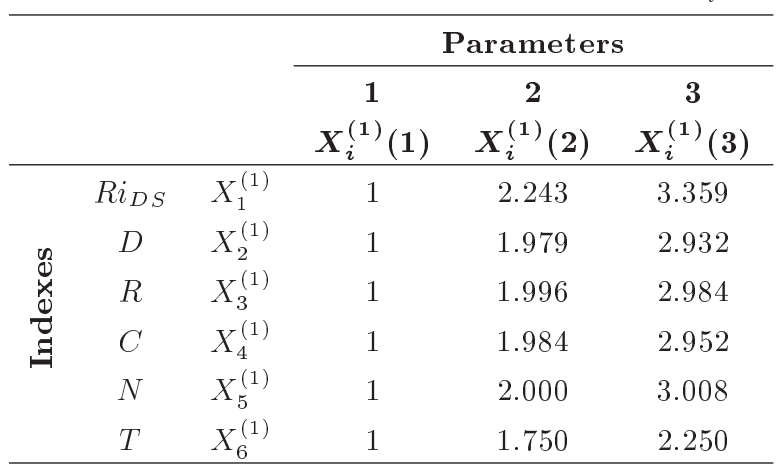

calculated by Eq. (1). Then, matrix $B$ is established through Eq. (2). The sequence $Y_{N}$ stands for a data vector determined by Eq. (3). The vector is shaped by the data in Table 9 , excluding those in the first row and in the first column. In the second step, the sequence $\hat{a}$ is formed by Eq. (4) based on the matrix $B$ and the sequence $Y_{N}$.

$$
\begin{aligned}
& Z_{1}^{(1)}(k)=-\left[x_{1}^{(1)}(k-1)+x_{1}^{(1)}(k)\right] / 2, \\
& B=\left[\begin{array}{llll}
z_{1}^{(1)}(2) & x_{2}^{(1)}(2) & L & x_{6}^{(1)}(2) \\
z_{1}^{(1)}(3) & x_{2}^{(1)}(3) & L & x_{6}^{(1)}(3)
\end{array}\right] \\
& =\left[\begin{array}{llllll}
-1.622 & 1.979 & 1.966 & 1.984 & 2.000 & 1.750 \\
-2.801 & 2.932 & 2.984 & 2.952 & 3.008 & 2.250
\end{array}\right] \text {, } \\
& Y_{N}=\left[x_{1}^{(0)}(2), x_{1}^{(0)}(3)\right]^{T}=[1.243,1.116]^{T},
\end{aligned}
$$

\begin{tabular}{|c|c|c|c|c|c|c|}
\hline \multirow[b]{2}{*}{ Sample } & \multicolumn{6}{|c|}{ Influence factors } \\
\hline & $D$ & $\boldsymbol{R}$ & $C(\%)$ & $N$ (timing) & $T\left({ }^{\circ} \mathrm{C}\right)$ & $D S$ (timing. $\left.\mathrm{mm}^{-1}\right)$ \\
\hline SMA-1 & 0.8963 & 2.60 & 6.2 & 60.0 & 24 & 5002 \\
\hline SMA-2 & 0.8777 & 2.59 & 6.1 & 60.0 & 18 & 6220 \\
\hline SMA-3 & 0.8544 & 2.57 & 6.0 & 60.5 & 12 & 5583 \\
\hline
\end{tabular}

Table 8. Rutting test data for the three gradations of Stone Matrix Asphalt (SMA) mixtures. 


$$
\begin{aligned}
\hat{a} & =B^{T} B^{-1} B^{T} Y=\left[a, b_{1}, b_{2}, \cdots, b_{n}\right]^{T} \\
& =[1.605,2.112,1.083,0.570,-0.156,-0.444]^{T},
\end{aligned}
$$

where $Z_{(1)}^{(1)}(k)$ stands for the average of the series of consecutive neighbors from $x_{1}^{(1)}(k-1)$ to $x_{1}^{(1)}(k)$ shown in Table 10. $x_{i}^{(1)}(2)$ and $x_{i}^{(1)}(3)$ are also given in Table 10 and $x_{1}^{(0)}(i)$ is in Table 9 . The letter $a$ represents development coefficient and $b_{i}$ is the driving coefficient for preparing to establish the grey model $\operatorname{GM}(1,6)$.

3. Calculating the raw data time response value $\hat{x}_{1}^{(0)}$. Eq. (5) is achieved by substituting $\hat{a}$ into Eq. (6) and it is called whitening equation of the GM (1, 6). Eq. (7) is an approximate time response of Eq. (5). The response $\hat{x}_{1}^{(1)}$ of the main sequence is composed of the experimental data for the mixtures of the three gradations, which is calculated by substituting the influence factor series $X_{2}^{(1)} \sim X_{6}^{(1)}$ into Eq. $(7) . \hat{x}_{1}^{(0)}$ indicates the dynamic stability of SMA mixtures obtained by the sequence $\hat{x}_{1}^{(1)}$ through a regressive and initial reduction.

$$
\begin{gathered}
\left(d x_{1}^{(1)} / d t\right)+1.605 x_{1}^{(1)}=2.112 x_{2}^{(1)}+1.083 x_{3}^{(1)} \\
-0.1562 x_{4}^{(1)}-0.444 x_{5}^{(1)}+0.57 x_{6}^{(1)}, \\
\left(d x_{1}^{(1)} / d t\right)+a x_{1}^{(1)}=b_{2} x_{2}^{(1)}+b_{3} x_{3}^{(1)} \\
\hat{x}_{1}^{(1)}(k+1)=\left(x_{1}^{(1)} 0-0.623 \sum_{i=2}^{6} b_{i} x_{i}^{(1)}(k+1)\right) \\
e^{-1.605 k}+0.623 \sum_{i=2}^{6} b_{i} x_{i}^{(1)}(k+1)
\end{gathered}
$$

$$
k=1,2,3
$$

where $\hat{x}_{1}^{(1)}(k+1)$ indicates response value of dynamic stability at the $k+1$ th SMA mixture. $x_{1}^{(1)}(0)$ is constant and equal to $1 . x_{i}^{(1)}(k+1)$ shows that the primitive data are processed by initialization and then, first-order accumulation.

4. Establishing the prediction model. According to the above research findings, the calculation model for dynamic stability of SMA mixtures is established based on the results for fractal dimension $D$, relative coefficient $R$, asphalt content $C$, rolling times $N$, and testing temperature $T$, as given in Eq. (8):

$$
\begin{aligned}
& \hat{x}_{1}^{(1)}(k+1)= {\left[1-\frac{1}{a} \sum_{i=2}^{6} b_{i} x_{i}^{(1)}(k+1)\right] e^{-a k} } \\
&+\frac{1}{a} \sum_{i=2}^{6} b_{i} x_{i}^{(1)}(k+1), \\
& \hat{x}_{1}^{(0)}(k+1)= {\left[\hat{x}_{1}^{(1)}(k+1)-\hat{x}_{1}^{(1)}(k)\right] \times 5002, } \\
& k \geq 3
\end{aligned}
$$

where $\hat{x}_{1}^{(0)}(k+1)$ stands for the prediction value of dynamic stability of SMA mixture. The coefficient $\hat{x}_{1}^{(1)}(k)$ is the response value of the dynamic stability of the $k$ th SMA mixture.

It is observable that the dynamic stability of SMA mixtures has a positive correlation with fractal dimension and relative coefficient. Also, the anti-rutting performance of SMA mixtures with higher amounts of coarse aggregate is better than SMA mixtures with fine aggregate, which is in agreement with the experimental results for rutting resistance. Asphalt content has a positive relation to the dynamic stability of SMA mixtures and appropriate increase in asphalt content can improve the adhesion and density of aggregate particles, which is beneficial to improving rutting resistance of SMA mixtures. The correlation of testing temperature with dynamic stability in SMA mixtures is negative, that is, the higher the temperature, the lower the dynamic stability of the asphalt mixture. This finding is in accordance with experimental results. Also, there is a negative correlation between rolling times and dynamic stability. The reason is that the frame structure formed with coarse aggregates in SMA mixtures is destroyed by over-rolling. As a result, the mixture gradually turns into an $\mathrm{AC}$ one and its resistance to rut deformation decreases.

\section{Summary and conclusion}

In this study, the rutting resistance of SMA mixtures was investigated though laboratory tests under different influencing factors and a dynamic stability prediction model based on the test data was established. The main research conclusions are as follows:

- For SMA mixtures, the optimum asphalt dosage (OAC) in Marshall test is not in agreement with that in wheel tracking test $\left(\mathrm{OAC}^{\prime}\right)$ and they have the following relationship: $O A C=O A C+0.1 \% \sim 0.3$;

- With increase in asphalt dosage, the dynamic stability of SMA mixtures tends to increase at the beginning and decrease afterwards. The curves of bitumen content and dynamic stability have an almost parabolic relationship. On the other hand, 
with too much or too little compaction work, the rutting resistance of SMA mixtures is reduced. When temperature increases by $0.5^{\circ} \mathrm{C}$, the dynamic stability of SMA mixtures is reduced by an average of $18.6 \%$. Higher amounts of aggregate and powder lead to lower anti-rutting performance of SMA mixtures;

- Dynamic stability of SMA mixtures has a positive correlation with fractal dimension, relative coefficient, and asphalt dosage. Also, it has a negative correlation with rolling times and testing temperature.

\section{Acknowledgments}

The author would like to acknowledge the financial supports of Shaanxi University of Technology through Talent Introduction Fund (SLGQD16-11) and Key R \& D Program of Shaanxi Province, China (2020SF-430).

\section{References}

1. Ahmadinia, E., Zargar, M., Karim, M.R., Abdelaziz, M., and Ahmadinia, E. "Performance evaluation of utilization of waste polyethylene terephthalate (PET) in stone mastic asphalt", Construction \& Building Materials, 36(6), pp. 984-989 (2012).

2. Tayfur, S., Ozen, H., and Aksoy, A. "Investigation of rutting performance of asphalt mixtures containing polymer modifiers", Construction \& Building Materials, 21(2), pp. 328-337 (2007).

3. Wong, W.G., Han, H., He, G., Wang, K.C.P., and Lu, W. "Rutting response of hot-mix asphalt to generalized dynamic shear moduli of asphalt binder", Construction \& Building Materials, 18(6), pp. 399-408 (2004).

4. Aravind, K. and Das, A. "Pavement design with central plant hot-mix recycled asphalt mixes", Construction \& Building Materials, 21(5), pp. 928-936 (2007).

5. Xiao, F., Amirkhanian, S., and Juang, C.H. "Rutting resistance of rubberized asphalt concrete pavements containing reclaimed asphalt pavement mixtures", Journal of Materials in Civil Engineering, 19(6), pp. 475-483 (2007).

6. Chiu, C.T. and Lu, L.C. "A laboratory study on stone matrix asphalt using ground tire rubber", Construction \& Building Materials, 21(5), pp. 1027-1033 (2007).

7. Al-Hadidy, A.I. and Tan, Y.Q. "Mechanistic approach for polypropylene-modified flexible pavements", Materials \& Design, 30(4), pp. 1133-1140 (2009).

8. Ahmadinia, E., Zargar, M., Karim, M.R., Abdelaziz, M., and Shafigh, P. "Using waste plastic bottles as additive for stone mastic asphalt", Materials \& Design, 32(10), pp. 4844-4849 (2011).
9. Al-Hadidy, A.I. and Tan, Y.Q. "Mechanistic analysis of ST and SBS-modified flexible pavements", Construction \& Building Materials, 23(8), pp. 2941-2950 (2009).

10. Behnood, A. and Ameri, M. "Experimental investigation of stone matrix asphalt mixtures containing steel slag", Scientia Iranica, 19(5), pp. 1214-1219 (2012).

11. Meng, S.T. and Wei, D.X. "Research on anti-rutting performance of SMA asphalt pavement", Journal of Highway and Transportation Research and Development, 22(12), pp. 5-8 (2005).

12. Austroads, Technical note 16 "Stone mastic asphalt", ARRB. Transport Research (2004).

13. Asi, I.M. "Laboratory comparison study for the use of stone matrix asphalt in hot weather climates", Construction \& Building Materials, 20(10), pp. 982989 (2006).

14. Zhou, W., Huang, X., and Wang, L. "Study on the void reduction behavior of porous asphalt pavement based on discrete element method", International Journal of Pavement Engineering, 18(4), pp. 285-291 (2017).

15. Zhang, Z.Q., Qin, R.P., and Zhang, D.L. "Study of stone mastic asphalt performance", China Journal of Highway and Transport, 14(2), pp. 13-17 (2001).

16. Sharma, V. and Goyal, S. "Comparative study of performance of natural fibres and crumb rubber modified stone matrix asphalt mixtures", Revue Canadienne De Génie Civil, 33(2), pp. 134-139 (2006).

17. Huang, J., Xiang, Z., and Peng, H. "Systemic design and construction technology of stone matrix asphalt mixture", Journal of Tongji University, 34(1), pp. 6973 (2006).

18. Prowell, B.D., Watson, D.E., Hurley, G.C., and Brown, E.R. "Evaluation of stone matrix asphalt (SMA) for airfield pavements", NCAT Report 04-04, Auburn University (2009).

19. Guo, R., Hong, G., Li, P., and Wang, H. "Experiment analysis on high-temperature stability of AC-16 asphalt mixture", Journal of Changan University, 33(2), pp. 10-15 (2013).

20. Brown, E.R., Mallick, R.B., Haddock, J.E., and Bukowski, J. "Performance of stone matrix asphalt (SMA) mixtures in the United States", NCAT Report No. 97-1, Auburn University, Alabama (1997).

21. Moghaddam, T.B., Karim, M.R., and Abdelaziz, M.A. "A review on fatigue and rutting performance of asphalt mixes", Scientific Research \& Essays, 6(4), pp. 670-682 (2011).

22. Alhadidy, A. and Hameed, A.T. "Minimizing the moisture damage and drain down of Iraqi SMA mixtures using waste additives", Tikrit Journal of Engineering Science, 18(3), pp. 68-80 (2013).

23. Shaffie, E., Ahmad, J., Arshad, A.K., and Kamarun, D. "Using nanopolyacrylate and nanocomposite as binder modifiers for stone mastic asphalt (SMA)", Applied Mechanics \& Materials, 802(753), pp. 381386 (2015). 
24. İskender, E. "Rutting evaluation of stone mastic asphalt for basalt and basalt-limestone aggregate combinations", Composites Part B Engineering, 54(9), pp. 255-264 (2013).

25. Xiang, J.Y., Zhu, X., and Sun, J. "Research of rutting resistance performance influencing factors of asphalt mixture", Petroleum Asphalt, 23(5), pp. 22-26 (2009).

26. Apeagyei, A.K., Mcghee, K.K., Clark, T., and Clark, T.M. "Influence of aggregate packing and asphalt binder characteristics on performance of stone matrix asphalt", Transportation Research Board 92nd Annual Meeting (2013).

27. Sarang, G., Lekha, B.M., Geethu, J.S., and Shankar, A.U.R. "Laboratory performance of stone matrix asphalt mixtures with two aggregate gradations", Journal of Modern Transportation, 23(2), pp. 130-136 (2015).

28. Chen, J.S., Hsieh, W., and Liao, M.C. "Effect of coarse aggregate shape on engineering properties of stone mastic asphalt applied to airport pavements", International Journal of Pavement Research \& Technology, 6(5), pp. 595-601 (2013).

29. Mogawer, W. and Stuart, K. "Effects of mineral fillers on properties of stone matrix asphalt mixtures", Transportation Research Record Journal of the Transportation Research Board, 1530(1), pp. 86-94 (1996).

30. AI-Etba, S.R.O., Sravana, D.P., and Kumar, S.A. "Studying properties of stone matrix asphalt mixture by altering aggregate gradations and filler types", International Journal Scientific Engineer Technology Research, 2, pp. 942-947 (2013).

31. Xie, H.B. "Determining the optimum compaction level for designing stone matrix asphalt mixtures", Thesis Dissertations, Auburn University, Alabama (2006).

32. Behbahani, H., Nowbakht, S., Fazaeli, H., and Rahmani, J. "Effects of fiber type and content on the rutting performance of stone matrix asphalt", Journal of Applied Sciences, 9(10), pp. 1980-1984 (2009).

33. The Ministry of Communications P.R.C., Standard Test Methods of Bitumen and Bituminous Mixtures for Highway Engineering, JTG E20-2011, pp. 195-197, China Communication Press, Beijing, China (2011).
34. Li, P., Wang, X.L., Li, H.S., and Qian, Y. "Influence factors and anti-rutting agent of high-temperature stability of asphalt mixture", rth International Conference on Traffic and Transportation Studies, Kunming, China, pp. 1293-1302 (2010).

35. Li, P., Nian, T.F., Zhang, Y.L., Ma, K., Guo, Y.F., and Zhao, Z.P. "Study on anti-shearing property of asphalt pavement for concrete bridge deck based on oblique shear test", Journal of Wuhan University of Technology, 37(11), pp. 48-53 (2015).

36. Li, P., Ma, K., Nian, T.F., Zhong, W.U., and Guo, Y.F. "Study on fracture theory and crack propagation test of asphalt mixture pre-notched beam based on weight function method", Journal of Highway \& Transportation Research \& Development, 11(1), pp. 713 (2016).

37. The Ministry of Communications P.R.C., Technical Specifications Construction of Highway Asphalt Pavements, JTG F40-2004, pp. 291-349, China Communication Press, Beijing, China (2004).

38. Lin, R.Y. and Sha, A.M. "Theory of fractal applied to the compression strength model of semi-rigid base", Journal of Wuhan University of Technology, 33(9), pp. 44-49 (2011).

39. Hao, Z. and Sha, A.M. "Analysis on the influences of material composition on semi-rigid base fatigue property", Journal of Wuhan University of Technology, 34(1), pp. 41-45 (2012).

\section{Biography}

Rui Guo is mainly engaged in teaching and research work on road materials in the School of Civil Engineering and Architecture at Shaanxi University of Technology, China. He received his BSc in Civil Engineering from Xi'an University of Architecture and Technology in 2007, MSc in Road Engineering with the specialty of road materials from Lanzhou University of Technology in 2010, and PhD also in Road Materials from Chang'an University in 2014. He is interested in continuing research activities in his field of specialty in the future. 